\title{
Size distributions of polycyclic aromatic hydrocarbons in urban atmosphere: sorption mechanism and source contributions to respiratory deposition
}

\author{
Yan Lv ${ }^{1}$, Xiang $\mathrm{Li}^{1}$, Ting Ting Xu${ }^{1}$, Tian Tao Cheng ${ }^{1}$, Xin Yang ${ }^{1}$, Jian Min Chen ${ }^{1}$, Yoshiteru Iinuma ${ }^{2}$, and \\ Hartmut Herrmann ${ }^{2}$ \\ ${ }^{1}$ Shanghai Key Laboratory of Atmospheric Particle Pollution and Prevention (LAP3), Department of Environmental Science \\ \& Engineering, Fudan University, Shanghai 200032, China \\ ${ }^{2}$ Leibniz-Institut für Troposphärenforschung (IfT), Permoserstr. 15, 04318 Leipzig, Germany
}

Correspondence to: Xiang Li (lixiang@ fudan.edu.cn) and Hartmut Herrmann (herrmann@ tropos.de)

Received: 28 March 2015 - Published in Atmos. Chem. Phys. Discuss.: 4 August 2015

Revised: 17 January 2016 - Accepted: 22 February 2016 - Published: 8 March 2016

\begin{abstract}
In order to better understand the particle size distribution of polycyclic aromatic hydrocarbons (PAHs) and their source contribution to human respiratory system, sizeresolved PAHs have been studied in ambient aerosols at a megacity Shanghai site during a 1-year period (2012-2013). The results showed the PAHs had a bimodal distribution with one mode peak in the fine-particle size range $(0.4-2.1 \mu \mathrm{m})$ and another mode peak in the coarse-particle size range (3.3$9.0 \mu \mathrm{m})$. Along with the increase in ring number of PAHs, the intensity of the fine-mode peak increased, while the coarsemode peak decreased. Plotting of $\log (\mathrm{PAH} / \mathrm{PM})$ against $\log \left(D_{\mathrm{p}}\right)$ showed that all slope values were above -1 , suggesting that multiple mechanisms (adsorption and absorption) controlled the particle size distribution of PAHs. The total deposition flux of PAHs in the respiratory tract was calculated as being $8.8 \pm 2.0 \mathrm{ng} \mathrm{h}^{-1}$. The highest lifetime cancer risk (LCR) was estimated at $1.5 \times 10^{-6}$, which exceeded the unit risk of $10^{-6}$. The LCR values presented here were mainly influenced by accumulation mode PAHs which came from biomass burning (24\%), coal combustion (25\%), and vehicular emission $(27 \%)$. The present study provides us with a mechanistic understanding of the particle size distribution of PAHs and their transport in the human respiratory system, which can help develop better source control strategies.
\end{abstract}

\section{Introduction}

Atmospheric PAHs are important contaminants in urban air because of their carcinogenic and mutagenic properties ( $\mathrm{Li}$ et al., 2006; Garrido et al., 2014). They mainly result from incomplete combustion of carbon-containing materials and can partition between the gas and the particulate phase (Fernández et al., 2002; Hytönen et al., 2009; Shen et al., 2011). This partitioning process strongly depends on particle sizes, PAH species and temperature, and it affects PAH transport, deposition, and degradation as well as health impacts. With regard to these, particle sizes distributions of PAHs play a critical yet poorly understood role. Of particular importance is the role played by high molecular mass PAHs because most of them are carcinogenic and associated with fine aerosol particles (Akyuz and Cabuk, 2009; Wu et al., 2014). Since inhalation deposition depends on particle sizes, these fine particles loaded with PAHs can travel deep into the human respiratory system and cause direct health impact (Kawanaka et al., 2009; K. Zhang et al., 2012). Current knowledge on PAH size distribution remains incomplete. Information is missing on partitioning mechanisms and health effects of PAHs. To address these concerns, further studies are necessary and important.

Over the past decade, numerous measurements of PAH size distribution have been repeatedly carried out in various areas around the world, such as Seoul (Korea; Lee et al., 2008); Saitama and Okinawa (Japan; Kawanaka et al., 2004; Wang et al., 2009); Mumbai and Delhi (India; 
Venkataraman et al., 1999; Gupta et al., 2011); Barcelona (Spain; Mesquita et al., 2014); Dresden (Germany; Gnauk et al., 2011); Birmingham (England; Delgado-Saborit et al., 2013); Lisbon (Portugal; Oliveira et al., 2011); Algiers (Algeria; Ladji et al., 2014); Beauharnois (Canada; Sanderson and Farant, 2005); Los Angeles, Massachusetts, Chicago, and Claremont (USA; Venkataraman and Friedlander, 1994; Allen et al., 1996; Offenberg and Baker, 1999; Miguel et al., 2004); and Tianjing, Beijing, and Guangzhou (China; Wu et al., 2006; Zhou et al., 2008; Yu and Yu, 2012). These studies, conducted in various countries and cities showed that most PAHs existed on small particles and had a similar modal distribution as isomers. PAH size distribution can vary with their releasing sources and particle aging processes (Venkataraman et al., 1994). In order to illustrate the partitioning mechanism of PAHs between particles, Venkataraman et al. (1999) developed the equilibrium adsorption and absorption theory, which explained the predominance of PAHs in nuclei and accumulation mode particles, respectively, but failed to explain it in coarse-mode particles. Allen et al. (1996) proposed that mass transfer by vaporization and condensation helped estimate the particle size distribution of PAHs. However, this theory did not account for particle deposition and particles' influence on residence time. Therefore, the mechanisms that govern PAH distribution in different size particles have not yet been identified and require further clarification. The fine particles discussed here can travel deep into the human respiratory system and, for the smallest particles, potentially enter the bloodstream, thus exposing people to both particles and the particle-bound compounds (Geiser et al., 2005). To solve these problems, the first thing we should clarify is the releasing source of size-specific PAHs as well as their transport characteristics in the human respiratory system (Chen and Liao, 2006; Sheesley et al., 2009).

The present study aims to conduct an ambient measurement on particle size distributions of PAHs associated with inhalation exposure at a megacity Shanghai site during a 1year period (2012-2013). The specific objectives are as follows: (i) to investigate particle size distributions of PAHs; (ii) to elaborate the mechanisms controlling PAH distribution among the different size particles; and (iii) to estimate the inhalation exposure and PAH source contribution.

\section{Experimental setup and methods}

\subsection{Chemicals}

All solvents were HPLC grade and bought from Tedia Company Inc., USA. Standard mixtures of PAHs were purchased from Sigma-Aldrich, Shanghai, China. The 16 EPA priority PAHs were investigated, i.e., naphthalene (NAP, two-ring), acenaphthylene (ANY, three-ring), acenaphthene (ANA, three-ring), fluorene (FLU, three-ring), phenanthrene (PHE, three-ring), an- thracene (ANT, three-ring), fluoranthene (FLT, four-ring), pyrene (PYR, four-ring), benz[ $a]$ anthracene (BaA, fourring), chrysene (CHR, four-ring), benzo[b]fluoranthene (BbF, five-ring), benzo[ $k]$ fluoranthene (BkF, five-ring), benzo $[a]$ pyrene (BaP, five-ring), dibenz $[a, h]$ anthracene (DBahA, five-ring), indeno[1,2,3-cd]pyrene (IPY, six-ring), and benzo[ghi]perylene (BghiP, six-ring). For the purpose of ease of discussion, we divided these PAHs into four groups, i.e., three- to six-ring PAHs based on their volatility and aromatic ring numbers (Allen et al., 1996; Duan et al., 2005, 2007).

\subsection{Sampling site}

The measurements took place on the rooftop ( $20 \mathrm{~m}$ above the ground) of teaching building no. 4 at Fudan University campus $\left(121.50^{\circ} \mathrm{E}, 31.30^{\circ} \mathrm{N}\right)$, approximately $5 \mathrm{~km}$ northeast of downtown Shanghai city (elevation about $4 \mathrm{~m}$ a.s.1.). This is a Fudan super monitoring station for atmospheric chemistry, operational all year round. More information on this site can be found in previous studies (X. Li, 2011; P. F. Li et al., 2011), and hence only a brief introduction is given. The site is located in a mixed-use neighborhood including many schools, supermarkets, and residences. The site is also in close proximity to two major streets, i.e., Handan Road (about $200 \mathrm{~m}$ south) and Guoding Road (about $300 \mathrm{~m}$ east). There is always heavy traffic in this area due to the local and cross-border traffic. The main releasing sources at this site include industries emissions, household heating, road transport, and biomass burning.

\subsection{Sample collection and pretreatment}

An Anderson eight-stage air sampler (Tisch Environmental Inc., USA) was used to collect aerosol samples with different size ranges, i.e., 10.0 (inlet)-9.0, 9.0-5.8, 5.8-4.7, $4.7-3.3,3.3-2.1,2.1-1.1,1.1-0.7,0.7-0.4$, and $<0.4 \mu \mathrm{m}$ (backup filter). The flow rate of the sampler was controlled at $28.3 \mathrm{~L} \mathrm{~min}^{-1}$. The average collecting time for each batch of samples was $120 \mathrm{~h}$, and the air volume that passed through the sampler was $203.8 \mathrm{~m}^{3}$. The sampling campaign was conducted during the period December 2012-December 2013. A total of 189 size-segregated particle samples was obtained, including their corresponding sampling information and meteorological conditions.

Quartz fiber membranes (Whatman QMA, $\varnothing 81 \mathrm{~mm}$ ) were used to collect aerosol particle samples. Before use, the membranes were baked at $450^{\circ} \mathrm{C}$ for $4 \mathrm{~h}$, equilibrated at $20^{\circ} \mathrm{C}$ and $40 \%$ relative humidity for $24 \mathrm{~h}$, and then weighed. After sampling, the membranes were equilibrated at $20^{\circ} \mathrm{C}$ in a desiccator for $24 \mathrm{~h}$ and weighed again using the same procedure. Then, the membranes were stored in freezers at $-20^{\circ} \mathrm{C}$ until they were extracted. Extraction was performed as soon as possible to ensure minimal loss of volatile PAH species. The procedure applied for PAHs pre- 
treatment was Soxhlet extraction. Briefly, the filter samples were put in a Soxhlet apparatus and extracted in a refluxing dichloromethane-hexane mixture $(1: 1, v / v)$ for $36 \mathrm{~h}$. The temperature was controlled at $69^{\circ} \mathrm{C}$. After the extraction was completed, the contents were filtered by a $0.45 \mu \mathrm{m}$ PTFE membrane to remove insoluble particles and then concentrated to exactly $2 \mathrm{~mL}$ by rotary evaporator and under a gentle nitrogen stream. The final extracts were stored in the refrigerator for further quantitative and qualitative analysis. The detailed pretreatment procedure can be found elsewhere (Mai et al., 2003).

\subsection{Analytical procedure}

All samples were quantified for 16 PAHs by an Agilent 7890A Series gas chromotograph (GC) coupled to an Agilent 7000B Triple Quadrupole mass spectrometer (MS; GCMS-MS, Agilent Technologies Inc., USA) operated in electron ionization (EI) mode. The analysis was performed using the Multiple reaction monitoring (MRM) procedure. The separation was achieved with a HP-5MS capillary column $(30 \mathrm{~m} \times 0.25 \mathrm{~mm}$ i.d. $\times 0.25 \mu \mathrm{m})$. The GC oven temperature was programmed to rise from $70^{\circ} \mathrm{C}$ (held for $2 \mathrm{~min}$ ) to $280^{\circ} \mathrm{C}$ at $15^{\circ} \mathrm{C} \mathrm{min}^{-1}$ and finally to $310^{\circ} \mathrm{C}$ at $5^{\circ} \mathrm{C} \mathrm{min}^{-1}$ with a hold of $1 \mathrm{~min}$. The total program time was $23 \mathrm{~min}$. The temperatures of the injector, ion source, and transfer line were controlled at 310,300 , and $310^{\circ} \mathrm{C}$, respectively. Analyses were carried out in a constant-flow mode. Ultra highpurity Helium (99.999\%) was applied as carrier gas with a flow rate of $1.2 \mathrm{~mL} \mathrm{~min}^{-1}$. Nitrogen was used as collision gas.

Matrix-matched calibration curves (5 to $1000 \mathrm{ng} \mathrm{mL}^{-1}$ ) were obtained for all compounds on the GC-MS-MS instrument by plotting the compound concentration vs. the peak area and determining the $R^{2}$ using weighted linear regression $(1 / x)$ with the quantitative analysis software for GCMS-MS. Limits of detection (LODs) and limits of quantification (LOQs) were measured based on a signal-to-noise ratio of about 3 and 10, respectively. The average blank value was subtracted from each signal above the LOD. Recovery tests were used to estimate possible losses of PAHs during the extraction process. The blank filters were spiked with the standard mixture and went through the same procedures for analysis. The results $(n=3)$ showed that the mean recoveries ranged from 70 to $100 \%$ for all PAHs. All concentrations reported were corrected by their respective recovery percentage.

\subsection{Statistical analysis}

Statistical analysis was carried out using partial leastsquares regression (PLS) procedure in the SIMCA-P software (Version 11.5, Umetrics Inc., Umeå, Sweden). The sizesegregated particles and corresponding PAH content were, respectively, used as $Y$ variables and $X$ variables in the PLS model. All variables were centered and scaled to unit variance before the analysis. In this way, all variables contributed with equal weight to the model. An important parameter in PLS analysis is the cross-validation correlation coefficient $\left(\mathrm{O}^{2}\right)$, which is calculated from the predicted residual sum of squares and can give an evaluation of the model's predictive ability in SIMCA (Lindgren et al., 1995). A large $\mathrm{O}^{2}$ value $(>0.5)$ means that the PLS model has a predictivity better than chance. In addition, the observed vs. predicted plot can give more direct displays for the values of the selected response. The correlation coefficient $\left(R^{2}\right)$ between observed and predicted values can be utilized to evaluate of the goodness of model fit. Generally, an $R^{2}$ value higher than 0.8 indicates that the PLS model fits the data well.

\subsection{PMF source apportionment}

Source apportionment of the size-resolved PAHs was performed using Positive Matrices Factorization (PMF). In the following, PMF will be outlined briefly (Larsen and Baker, 2003; Ma et al., 2010). By analyzing measured concentrations at receptor sites, the method can identify a set of factors which can be taken to represent major emission sources (Paatero and Tapper, 1994). PMF models are expressed as follows:

$x_{i j}=\sum_{k=1}^{p} g_{i k} f_{k j}+e_{i j}$,

where $X$ is a data matrix of $i$ by the $j$ th dimension, in which $i$ is the number of the size-segregated particle samples and $j$ is the number of the measured PAH species. $f_{k j}$ is the concentration of the $j$ th PAH species in the emissions from the $k$ th source; $g_{i k}$ is the contribution of the $k$ th source to the $i$ th particle sample. $e_{i j}$ is the portion of the measured concentration that cannot be explained by the model.

By incorporating an uncertainty for each observation $u_{i j}$, the PMF solution can minimize the objective function $Q$ (Eq. 2),

$Q=\sum_{i=1}^{n} \sum_{j=1}^{m}\left[\frac{x_{i j}-\sum_{k=1}^{p} g_{i k} f_{k j}}{u_{i j}}\right]^{2}$.

The PMF model requires data on measured PAH concentrations for all samples, together with information on the associated uncertainties. The confidence of results can be maintained by adjusting the data uncertainties. This allows us to lower the importance of these data through the least squares fit. The work presented here is the US Environmental Protection Agency positive matric factorization (EPA PMF) version 3.0. Please find more information about this on the US EPA website (http://www.epa.gov/air-research/positivematrix-factorization-model-environmental-data-analyses). 


\subsection{Human respiratory risk assessment}

In order to evaluate the influence of the size-resolved PAHs on human respiratory potential, we adopted an International Commission on Radiological Protection (ICRP) model (ICRP, 1994) for these. Based on inhaled particles sizes, the respiratory tract was divided into three main deposition regions: head airway (HA), tracheobronchial region (TB), and alveolar region (AR). The PAH concentrations were loaded into the ICRP model to calculate the deposition efficiency and flux of inhaled PAHs.

Lifetime cancer risk (LCR) was applied to assess the cancer risk associated with exposure to the size-resolved PAHs through inhalation of ambient particles (Kawanaka et al., 2009; K. Zhang et al., 2012). The LCR was calculated by the formula (US EPA, 1989)

$\mathrm{LCR}=\mathrm{EI} \times \mathrm{ED} \times \mathrm{CSF} /(\mathrm{AT} \times \mathrm{BW})$,

where EI was the estimated inhalation rate $\left(\mathrm{mg} \mathrm{d}^{-1}\right)$, which was calculated by deposition fluxes $\left(\mathrm{mg} \mathrm{h}^{-1}\right)$ and daily exposure time $\left(12 \mathrm{~h} \mathrm{~d}^{-1}\right)$, ED was the exposure duration for an adult (30 years), CSF was the inhalation cancer slope factor $\left(\left(\mathrm{mg} \mathrm{kg}^{-1} \mathrm{~d}^{-1}\right)^{-1}\right)$, BW was the body weight $(\sim 60 \mathrm{~kg})$, and AT was the average lifetime for carcinogens (assuming 70 years for adults). LCR for exposure to PAHs in this paper was based on the sum of $\mathrm{BaP}$ equivalent concentration $\left(\mathrm{BaP}_{\mathrm{eq}}\right)$, which was calculated by multiplying each concentration by its individual toxic equivalency factor (TEF) (Nisbet and Lagoy, 1992). As suggested by the Office of Environmental Health Hazard Assessment (OEHHA), a value of 3.9 for $\mathrm{BaP}$ was usually applied as a recommended value for the calculation of CSF in LCR formula (Liu et al., 2007).

\section{Results and discussion}

\subsection{Occurrence and size distribution of PAHs}

Figure 1 presents the time variation of the total PAHs, sizesegregated particles, visibility, and relative humidity (RH) during the sampling period. Results show that high PAHs episodes coincide with high PM levels, along with the low $\mathrm{RH}$ and low visibility. Average total PAH concentrations adsorbed on particles range from 41.6 to $66.6 \mathrm{ng} \mathrm{m}^{-3}$ (average: $48.7 \mathrm{ng} \mathrm{m}^{-3}$ ). The concentration of total particles during the observation period varies from 54.8 to $209.6 \mu \mathrm{g} \mathrm{m}^{-3}$ (average: $122.8 \mu \mathrm{g} \mathrm{m}^{-3}$ ). Among them, the daily $\mathrm{PM}_{2.5}$ concentration is $61.8 \mu \mathrm{g} \mathrm{m}^{-3}$, which is obviously higher than the annual (daily) national air quality standard of $10(25) \mu \mathrm{g} \mathrm{m}^{-3}$ set by the World Health Organization (WHO, 2006). Most particle masses are found in the accumulation mode size ranges $(0.4-2.1 \mu \mathrm{m})$. Fine particles are typically higher than coarse particles in Shanghai air. This finding is consistent with previous research on particle size distribution in Shanghai (Wang et al., 2014). The $\mathrm{PM}_{2.5} / \mathrm{PM}_{10}$ ratio of 50( \pm 8$) \%$

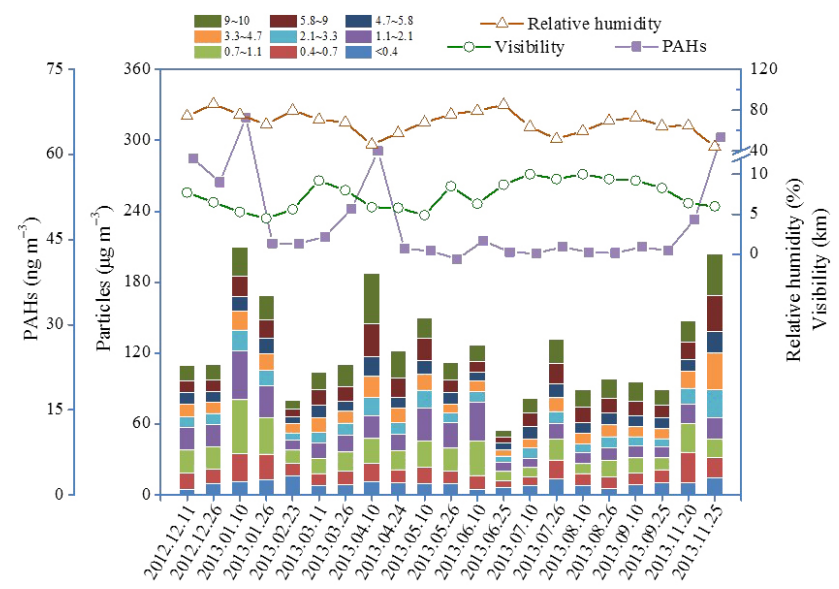

Figure 1. The sampling time series of PAH concentration $\left(\mathrm{ng} \mathrm{m}^{-3}\right)$, size-segregated particles $\left(\mu \mathrm{g} \mathrm{m}^{-3}\right)$, temperature $\left({ }^{\circ} \mathrm{C}\right)$, visibility $(\mathrm{km})$, and relative humidity $(\%)$.

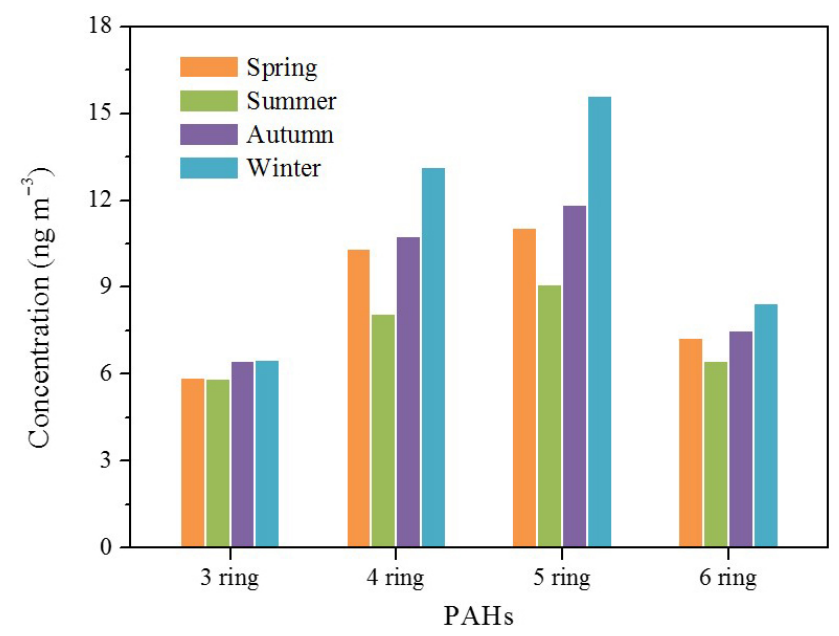

Figure 2. Seasonal variation of three- to six-ring PAHs.

suggests that the anthropogenic component of particle matter as represented by the $\mathrm{PM}_{1}$ fraction is significant in the studied area (Theodosi et al., 2011).

For the investigation of seasonal trends, the PAH data are divided into four seasonal groups, i.e., spring (March to May), summer (June to August), autumn (September to November), and winter (December to February). Figure 2 shows seasonal variation of PAH average concentration in aerosol particles. Results indicate that the mean concentration of particle-bound PAHs undergoes distinct seasonal variation, i.e., the highest levels are found in cooler seasons, while lowest or those below the detection limit are found during warmer seasons. The most abundant PAH species in winter are five- and four-ring PAHs (16 and $13 \mathrm{ng} \mathrm{m}^{-3}$ ), followed by six- and three-ring PAHs (7.5 and $6.5 \mathrm{ng} \mathrm{m}^{-3}$ ). Given these data, it can be noted that the season variation and particle size influence the concentration of PAHs. Shanghai 

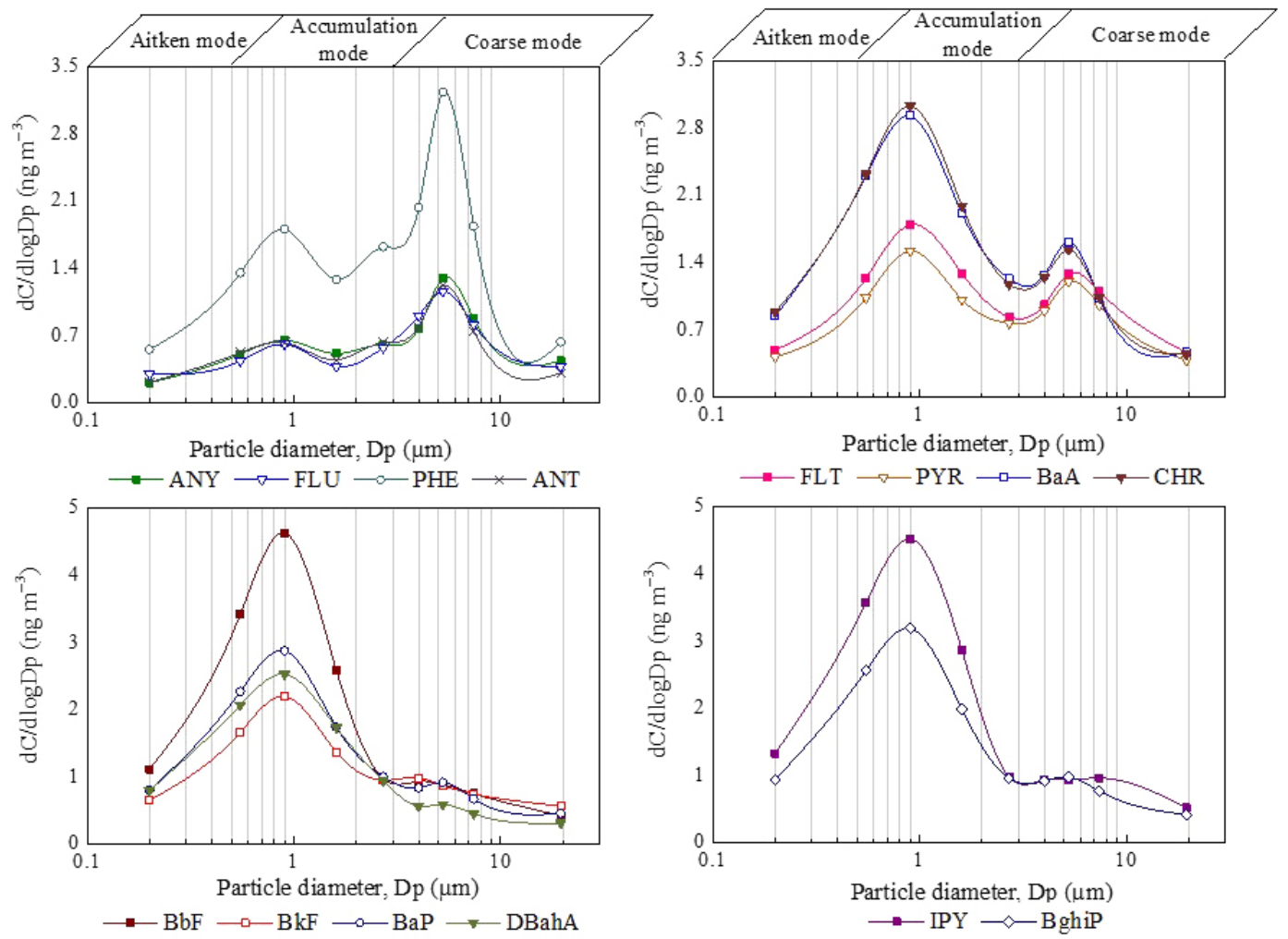

Figure 3. Particle size distribution of PAHs for all samples. $\mathrm{d} C$ is the concentration on each filter, $C$ is the sum concentration on all filters, and $\operatorname{d} \log D_{\mathrm{p}}$ is the $\log$ arithmic size interval for each impactor stage in aerodynamic diameter $\left(D_{\mathrm{p}}\right)$.

is situated in the subtropics along the east coast of China. The seasonal variation of weather in Shanghai is closely related to and controlled by the northern subtropical monsoon system. In winter, the popular northwest wind can drive the air pollutants from the north Chinese mainland to Shanghai, while in summer, the popular southeast wind can bring clean oceanic air mass from the Pacific Ocean to Shanghai. In cold seasons (winter and autumn), elevated winterand fall-PAH concentrations, particularly at urban sites, are most likely due to the higher level of fresh emissions from primary sources (such as wood smoke and vehicular emissions). Moreover, cold ignition of gasoline-powered vehicles during cold seasons may lead to an increase in the level of high molecular weight PAHs such as four- to six-ring PAHs (Arhami et al., 2010). The atmospheric conditions in winter, such as low temperatures, low intensity of solar radiation, and decreased PAH photodegradation, also favor the condensation and adsorption of PAHs on suspended particles that are present in urban air. On the other hand, in warm seasons (summer and spring), the concentrations of PAHs are reduced, possibly due to the high temperatures, higher mixed layer height, and heavy rainfall that may effectively remove particle-bound PAHs from the atmosphere. Additionally, high temperature and solar radiation favor the photochemical oxidation of PAHs. This seasonal pattern has been reported in many urban atmospheres (Teixeira et al., 2012; van Drooge and Ballesta, 2009; Ma et al., 2010). More details will be included in the following mode discussion and source attribution of PAHs.

To better describe PAH distribution, the particle fractions are divided into three modes: Aitken $\left(D_{\mathrm{p}}<0.4 \mu \mathrm{m}\right)$, accumulation $\left(0.4<D_{\mathrm{p}}<2.1 \mu \mathrm{m}\right)$, and coarse $\left(D_{\mathrm{p}}>2.1 \mu \mathrm{m}\right)$ mode. The Aitken and accumulation modes together constitute "fine" particles. We plot a $\log -\log$ chart, i.e., $\mathrm{d} C / \mathrm{d} \log D_{\mathrm{p}}$ against $D_{\mathrm{p}}$ (particle diameter) on the log scale, in which $\mathrm{d} C$ is the PAH concentrations in each particle size bin and $\operatorname{d} \log D_{\mathrm{p}}$ is the size width of each impactor channel (Kawanaka et al., 2004; Venkataraman and Friedlander, 1994; Venkataraman et al., 1999). Figure 3 clearly shows that most PAHs have a bimodal particle size distribution which contains one mode peak in the accumulation size range (0.4$2.1 \mu \mathrm{m})$ and another mode peak in coarse size range (3.3$9.0 \mu \mathrm{m})$. As the number of PAHs' aromatic rings increases, the intensities of two peaks vary a lot, i.e., the accumulation mode peak increases, while the coarse-mode peak decreases and even disappears in five- and six-ring PAHs. This is due to the fact that less volatile PAH species preferentially condense on fine particles and more volatile ones are inhibited on smaller particles because of the Kelvin effect (Hien et al., 2007; Keshtkar and Ashbaugh, 2007). This kind 
of mode distribution that appears in Shanghai is similar to those found in Mumbai, India (Venkataraman et al., 1999), but different from those in Boston, MA (Allen et al., 1996). From the results of PAH distribution, we see an important implication regarding health hazards from inhalation exposure. Since the majority of high molecular weigh PAHs has mutagenic and/or carcinogenic properties and almost exclusively exists on fine particles, these PAHs can travel deep into the human respiratory system and hence can pose a serious health risk through exposing a person to both particles and the loaded carcinogenic PAHs (Kameda et al., 2005).

\subsection{Atmospheric processing and partitioning mechanisms}

Previous studies on atmospheric process regarding PAHs have mainly focused on gas-particle partitioning (R. Zhang et al., 2012; McWhinney et al., 2013), but few studies are associated with the particle size distribution of PAHs. Thus, we use the size-resolved PAH data to assess the PAH aging and partitioning process among different size particles. Empirical evidence suggests that mass ratios of PAH to particulate matter (PAH / PM) can provide some valuable indications of PAH atmospheric processes. When PAH compounds and particles that are produced from incomplete combustion of organic material are released into the air, they can be expected to be involved in the particle aging process because some PAHs could be photooxidized to form SOA (secondary organic aerosol) and others might adsorb or absorb on preexisting particles via either self-nucleation or gas-particle partitioning. This would lead to an increase in atmospheric fine particulate matter (Kavouras et al., 1999; Kamens et al., 1999; Yu et al., 1999; Kamens and Jaoui, 2001; Chan et al., 2009). That is to say that the aging process can decrease the value of total-PAH / PM (Duan et al., 2005; Bi et al., 2005). Figure 4 shows the variation of total PAH / PM values across particle sizes. In general, PAH / PM ratios decrease gradually with the increase in particle size. This indicates that the different values of PAH / PM across particle size can be the result of different aging processes. In order to further verify the particle aging process, we use BaA / CHR as another indicator of particle aging. $\mathrm{BaA}$ is expected to be degraded more easily than $\mathrm{BaA}$ isomers during transport because of their higher reactivity. Using the ratios of a more reactive PAH compound to a less reactive one, such as $\mathrm{BaA} / \mathrm{CHR}$, An / Phe, and BaP / Bep, a higher ratio indicates relatively little photochemical processing of the air mass. On the other hand, a lower ratio is reflective of more aged PAHs. Therefore, it can be used to determine whether the air masses collected are fresh or aged (Ding et al., 2007). Figure 4 shows the decrease in $\mathrm{BaA} / \mathrm{CHR}$ with the increase in particle sizes, showing the same trend as PAH / PM. Generally, relatively higher ratios occur in small-particle size ranges, and lower ratios exist in large-particle size ranges, suggesting smaller particles sampled at urban sites are rel-

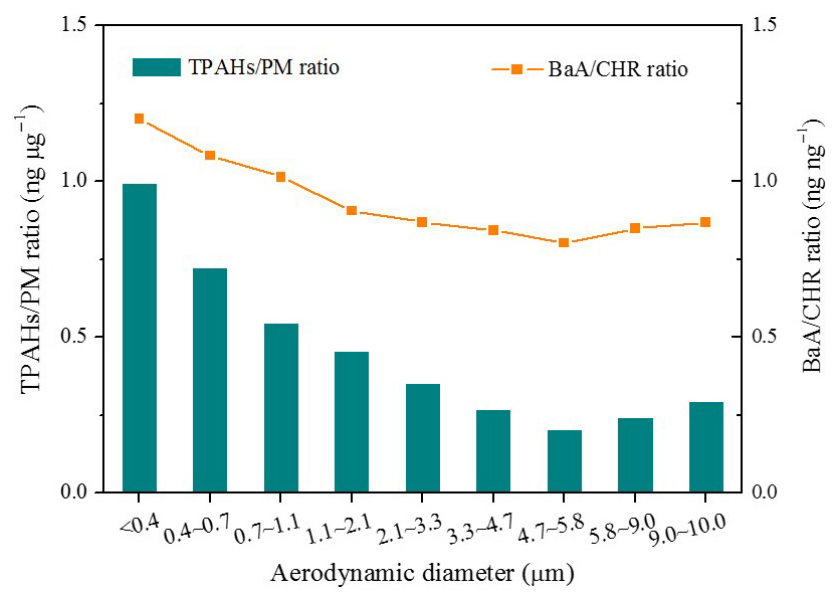

Figure 4. Ratios of total PAHs / PM (ng $\left.\mu g^{-1}\right)$ and $\mathrm{BaA} / \mathrm{CHR}$ $\left(\mathrm{ng} \mathrm{ng}^{-1}\right)$ across particle sizes.

atively fresh, while bigger particles are relatively aged. Because particulate-phase PAHs are susceptible to photodegradation, the decrease in $\mathrm{BaA} / \mathrm{CHR}$ with the increase in particle sizes shows that photodegradation plays an important role in the particle aging process, especially for the relatively larger urban aerosol particles. It should be noted that the explanation of particle aging in the present study still contains some uncertainties because of the scarcity of "aging time scale" data; therefore, further studies (e.g., theoretical models and chamber simulation experiment) are needed. Although the present results do not take the partitioning process into account directly, this study has taken advantage of the size-resolved PAH data to examine the governing mechanisms for particle size distribution.

Currently, the reliable mechanisms for controlling PAH distribution between different size particles include adsorption to nucleus particles, adsorption and absorption to accumulation particles, and multilayer adsorption on coarse particles (Venkataraman et al., 1999). Adsorption and absorption depend, respectively, on available particle surface area and organic mass. If PAHs are firstly associated with the particle surface, the PAH / PM mass ratio will show a $1 / D_{\mathrm{p}}$ dependence (assuming particles are spherical) and then will generate a straight line of slope -1 on a $\log$ vs. $\log$ axis (Venkataraman et al., 2002). Figure 5 shows that all slope values from the plots of $\log (\mathrm{PAH} / \mathrm{PM})$ against $\log \left(D_{\mathrm{p}}\right)$ are above -1 , suggesting that multiple mechanisms, i.e., adsorption and absorption, control the PAHs' distribution among different size particles. Moreover, the slope values decrease with the increase in ring number of PAHs, which means adsorption plays a much stronger role in the distribution process of five- and six-ring PAHs than three- and four-ring PAHs. The reason is the relatively lower volatility of fiveand six-ring PAHs, which makes them adjust to multiple adsorptive equilibria more slowly. Moreover, chemical affinities may also play an important role in the adsorption pro- 


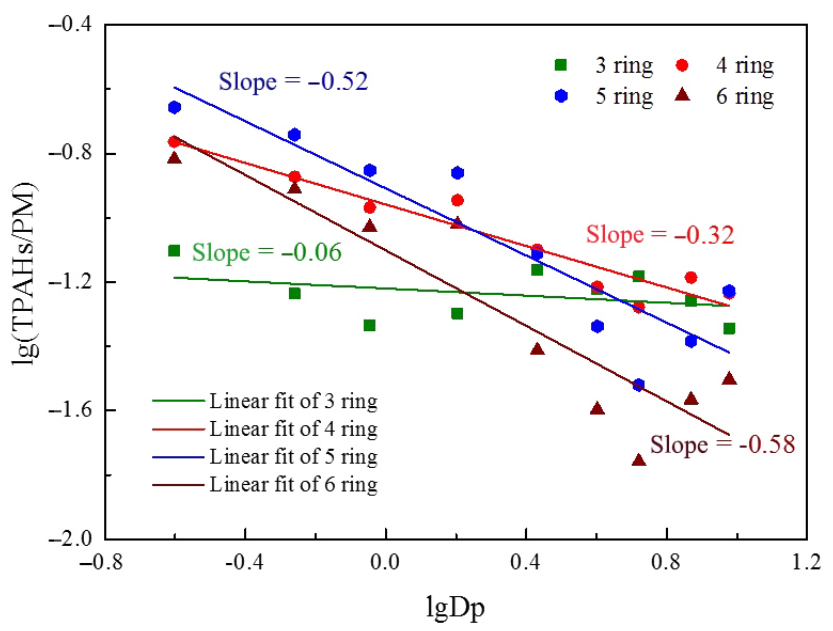

Figure 5. Plots of $\lg ($ TPAHs $/ \mathrm{PM})-\lg \left(D_{\mathrm{p}}\right)$ for PAHs with different ring numbers.

cess. Most five- and six-ring PAHs have a strong hydrophobicity and tend to affiliate with small particles because they can provide large surface areas (Venkataraman et al., 1999). Such an explanation, however, can not adequately account for PAHs' equilibrium mechanisms observed in the present study. Perhaps in fact five- and six-ring PAHs do not attain equilibrium due to the slow mass transfer, but they reach a steady state between the gaseous and particulate phases (Yu and $\mathrm{Yu}, 2012$ ).

\subsection{Statistical analysis}

In an attempt to understand how particle size affects PAH species, we built a statistical model using PLS regression based on PAH concentration and particle size data. After calculating, five components are adopted because they can give the most stable results and easily interpretable factors. The number of components in PLS is also consistent with the results of the PMF followed, as discussed in the next section. By plotting the observed (measured) particle sizes versus the predicted particle sizes, we obtain a goodness of fit with $R^{2}=0.87$, a goodness of prediction with $Q^{2}=0.80$, and a goodness of root mean square error (RMSE) with a value of 0.87 . Figure 6 shows the observed vs. predicted plot from the model. The plot performs well in predicting the size-resolved PAHs over the size range between 0.4 and $10 \mu \mathrm{m}$. There is no systematic underestimation (or overestimation), and most points fall close to the $45^{\circ}$ line. The results achieve the desired separation without overlap among nine particle size ranges. The model can explain $91 \%$ of $X$ and $87 \%$ of $Y$ and predict $80 \%$ of $Y$. These predictions are not de novo predictions, since all the data are part of the observed set. Nevertheless, these predicted results do validate the model effectiveness and the measured data reliability.

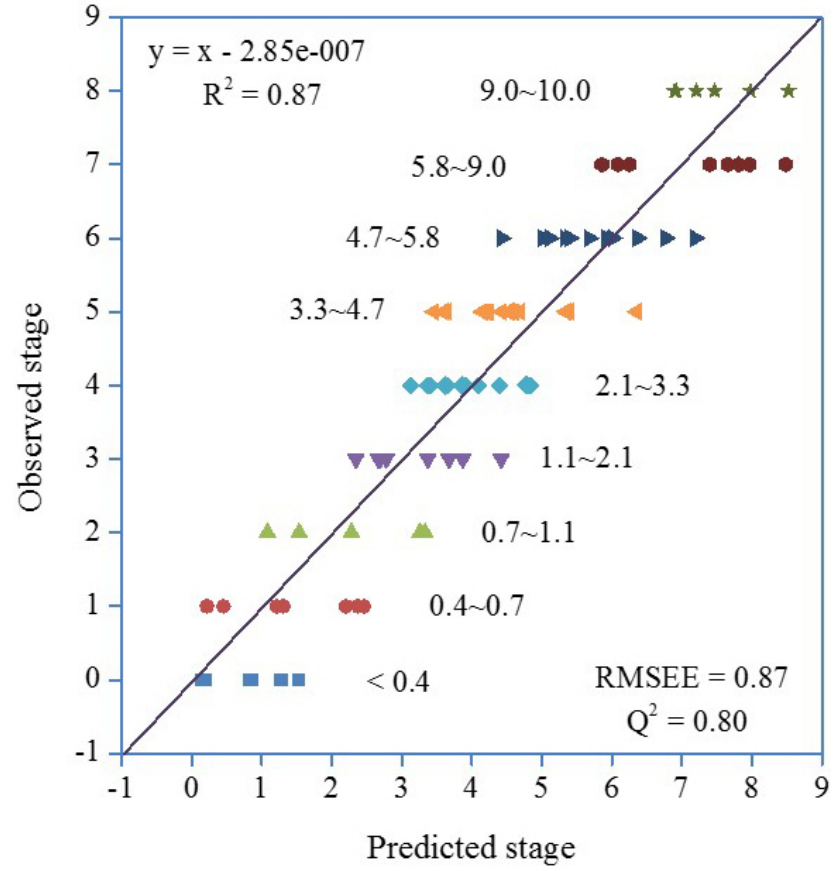

Figure 6. Measured and predicted total PAHs in all particles with sizes ranges from $<0.4$ to $10 \mu \mathrm{m}$. The dashed line represents the $45^{\circ}$ line.

Similarities between PAH profiles in the two adjacent sizes can be further identified by coefficient of divergence (CD), which is a self-normalizing parameter used to evaluate the divergence degree of two sets of data (Kong et al., 2012). CD is determined as follows:

$\mathrm{CD}_{j k}=\sqrt{\frac{1}{p} \sum_{i=1}^{p}\left(\frac{x_{i j}-x_{i k}}{x_{i j}+x_{i k}}\right)^{2}}$,

where $j$ and $k$ stand for the two adjacent particle fractions, $p$ is the number of investigated PAHs, and $x_{i j}$ and $x_{i k}$ represent the concentrations of PAHs species $i$ for size $j$ and $k$ (Kong et al., 2011). CD ranges from 0 to 1 . A low CD value $(<0.2)$ indicates a high level of homogeneity in PAH distribution between two adjacent sizes, while $C D$ values larger than 0.2 indicate heterogeneous PAH spatial distribution (Wilson et al., 2005). Figure 7 shows the PAHs' CD diagrams, which are distinguished by different colors. For the comparison between the adjacent sizes, most $\mathrm{CD}_{j k}$ values are less than 0.2, except $\mathrm{CD}_{0.4,0.4 \sim 0.7}(0.26)$ and $\mathrm{CD}_{1.1 \sim 2.1,2.1 \sim 3.3}(0.31)$, indicating that PAHs among $\mathrm{PM}_{0.4}, \mathrm{PM}_{0.4-2.1}$, and $\mathrm{PM}_{2.1-10}$ show a high spatial heterogeneity in source factor contributions.

\subsection{Emission source of size-resolved PAHs}

The different PAH distributions between fine and coarse particles may be attributed to different emission sources. By applying the PMF model, the optimal five main factors have 


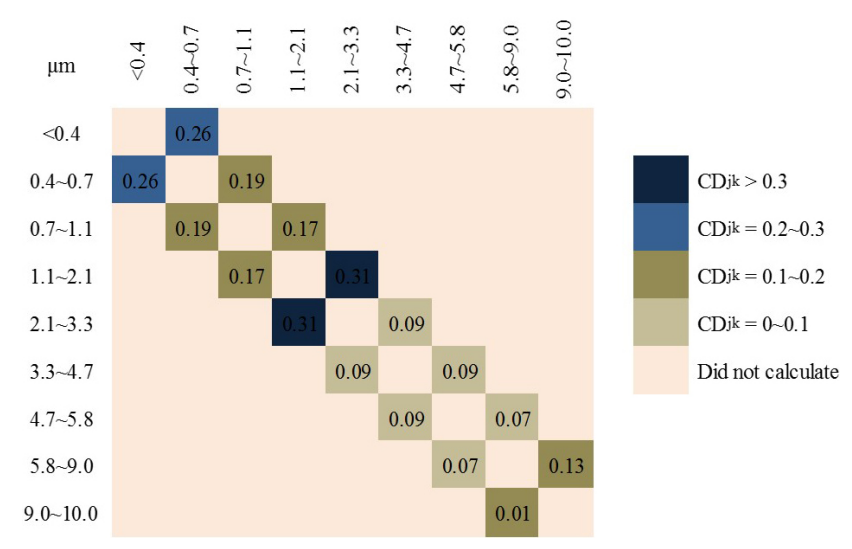

Figure 7. Similarity comparisons of PAHs profiles for the adjacent particles fractions.

been chosen after comparing three to seven factors. Five identified sources are, respectively, associated with vehicular emission, biomass burning, coal combustion, petroleum residue, and air-surface exchange. Figure 8 shows the profiles for all factors. Factor 1 presents a profile with high factor loadings for five- and six-ring PAHs, i.e., $\mathrm{B}(\mathrm{b}+\mathrm{k}) \mathrm{F}$, BaP, IPY, DBahA, and BghiP. These high molecular weight PAHs are reported as dominant in vehicle emissions (Bostrom et al., 2002; Ravindra et al., 2008). BbF and BkF are attributed to diesel motor vehicle emissions, while $\mathrm{BaP}$ and $\mathrm{BaA}$ are attributed to gasoline and diesel markers (Harrison et al., 1996; Sofowote et al., 2008). Thus, this factor is designated vehicular emissions without distinguishing between diesel and gasoline releasing. Factor 2 is dominated by high loadings of PHE, FLU, and BbF and moderate loadings of CHR, BkF, $\mathrm{BaA}$, IPY, and BghiP. This factor profile mainly comes from biomass burning that has been described in a previous study (Poulain et al., 2011). As the occurrence of biomass burning in Shanghai city is normally low, this source is most likely long-range transport, rather than local emission. Factor 3 is characterized by $\mathrm{B}(\mathrm{b}+\mathrm{k}) \mathrm{F}, \mathrm{CHR}, \mathrm{BaA}$, and BghiP. These compounds have been reported by different authors as coal combustion source markers (Yang et al., 2002; Lin et al., 2011). Although in Shanghai, natural gas is one of the main fuels used for domestic heating, there are still central heating systems using coal and petrol-derived fuels. Moreover, the influence of power plant, steel, and iron industries using coal as fuel may be also reflected in this factor. Factor 4 is mainly defined by four- and five-ring PAHs. High levels of these compounds, especially for PHE, are associated with crude-oil or refined-petroleum emissions and their degradation products (Zakaria et al., 2002). Thus, this factor is likely to represent petroleum residue or the derivatives of oil spill, leakage from vehicles, and discharge from municipal and industrial wastewater, etc. Factor 5 is more influenced by two- and three-ring PAHs. These PAHs are favored in air-surface exchange (Gigliotti et al., 2002). The "exchange" here means that the aged PAHs are probably released into the atmosphere again from contaminated soil or wastewater and then adsorbed later by the particles. Moreover, they also arrive here through long-range transport and finally deposition on particle surfaces. Thus, factor 5 is ascribed to air-surface exchange.

Figure 9 summarize the results of PAHs' source apportionment associated with factor contributions. As expected, the results are quite different for the different particle sizes. Coal combustion and biomass burning, respectively, accounted for 29 and $29 \%$ of accumulation mode PAHs as well as 12 and $13 \%$ of coarse-mode PAHs. Their contribution for particulate PAHs significantly decreases with the increase in particle size because large particles have large deposition velocities from the air. Air-surface exchange and petroleum residue account, respectively, for 9 and $10 \%$ of accumulation mode PAHs as well as 30 and $27 \%$ in coarse-mode PAHs. Note that the contribution of vehicle-derived PAHs (vehicular emission) are almost constant over all the year, i.e., they contribute $22 \%$ of accumulation mode PAHs and $18 \%$ of coarse-mode PAHs. In combination with PAH mode distribution, we know that high levels of PAHs occur in accumulation mode particles. Together with Aitken mode particles, we can obtain $80 \%$ of PAHs from the contribution of fine particles (Aitken and accumulation mode particles). It is apparent that these PAHs came from vehicle exhaust, coal combustion, and biomass burning.

\subsection{Respiratory exposure to PAHs}

In order to assess deposition efficiency and flux of sizeresolved PAHs in the human respiratory tract, we applied an International Commission on Radiological Protection (ICRP) model (1994). More details on calculating from the model are included elsewhere (K. Zhang et al., 2012; Kawanaka et al., 2009). The breath rate of inactive people is considered to be $0.45 \mathrm{~m}^{3} \mathrm{~h}^{-1}$. Figure 10 shows the deposition fluxes of size-resolved PAHs and their relative contributions in the head, tracheobronchial region, and alveolar region. We can find a flux peak value in accumulation mode particles (1.1-2.1 $\mu \mathrm{m})$, similar to the particle size distribution of PAHs as described previously (see Sect. 3.1). The total PAH deposition flux is $8.8 \pm 2.0 \mathrm{ng} \mathrm{h}^{-1}$, which is higher than that in indoor air of the urban community of Guangzhou, China $\left(3.7 \mathrm{ng} \mathrm{h}^{-1}\right.$ ) (K. Zhang et al., 2012), but it is lower than that to which traffice police in Beijing are exposed $\left(280 \mathrm{ng} \mathrm{h}^{-1}\right.$ at the respiratory rate of $0.83 \mathrm{~m}^{3} \mathrm{~h}^{-1}$ ) (Liu et al., 2007). Moreover, we find that the relative PAHs abundance varies a lot with the particle size. When particle size increases, the relative PAHs abundance increases in the head region, remains unchanged in tracheobronchial region, but decreases in the alveolar region. These results indicate that coarse particles contribute many PAHs in the head region, while fine particles contribute most PAHs in the alveolar region. These fine or ultrafine particles can also pass rapidly from the human 

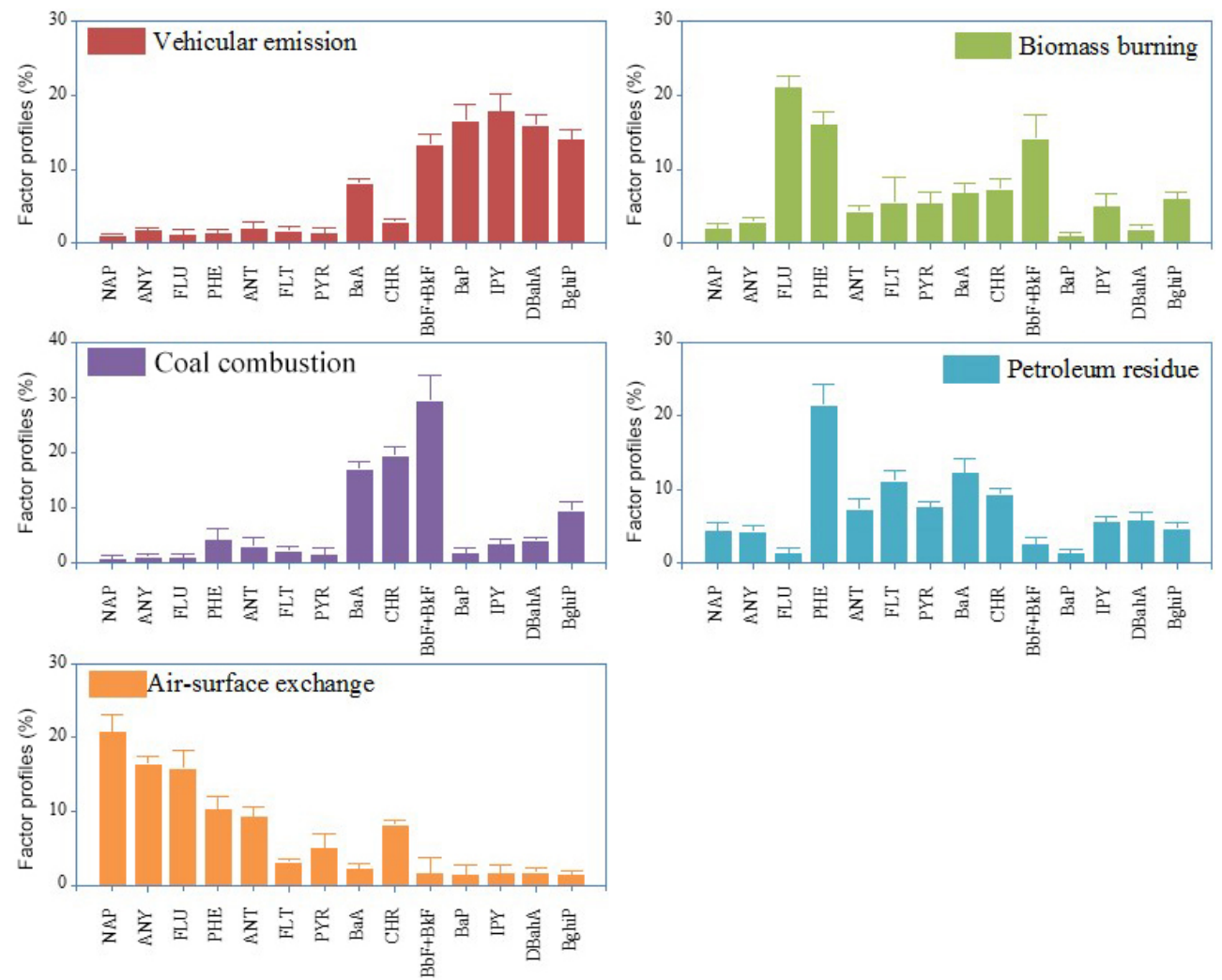

Figure 8. Profiles of the five factors resolved by the PMF model from all PAH data sets.

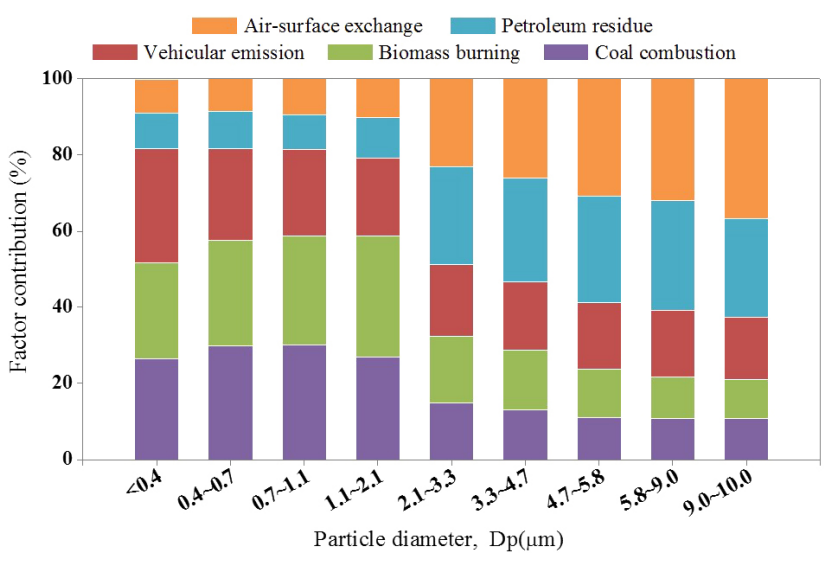

Figure 9. Factor contributions to size-segregated particles by the PMF model from full PAH data sets.

lung into the circulatory system, which may cause systematic exposure to PAHs (Nemmar et al., 2002).

Evaluating respiratory exposure needs to incorporate a consideration of the deposition efficiency of size-resolved PAHs. Deposition efficiency represents the deposition effectiveness of atmospheric PAHs in the human respiratory tract. The efficiency can then be calculated by the formula of the ICRP model. Figure 11 shows the regional deposition effi-

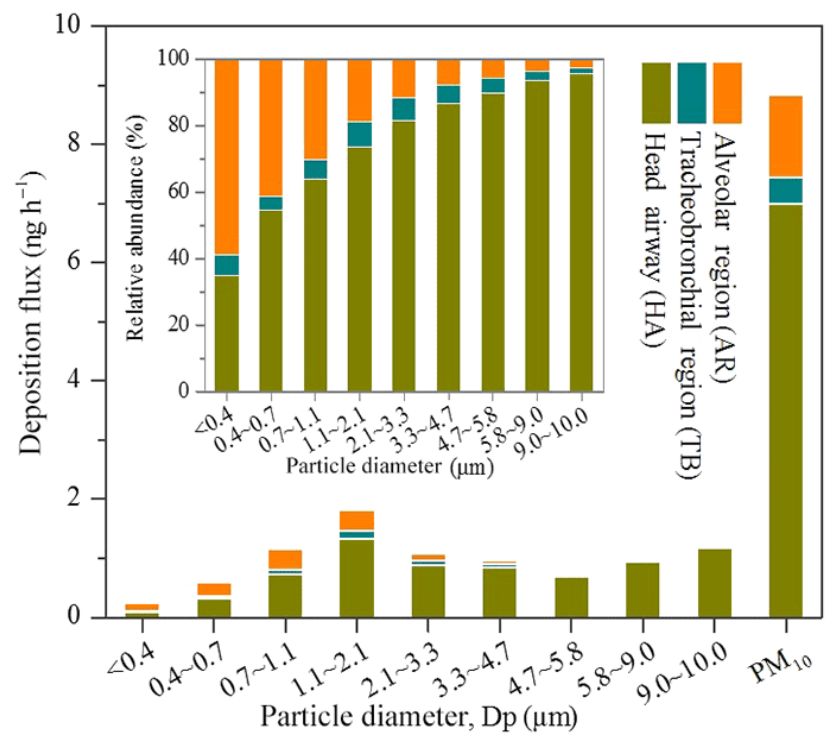

Figure 10. Deposition fluxes (estimated by the ICRP model) and relative abundance of the size-segregated PAHs in the head airway, tracheobronchial region, and alveolar region in the human respiratory tract. 


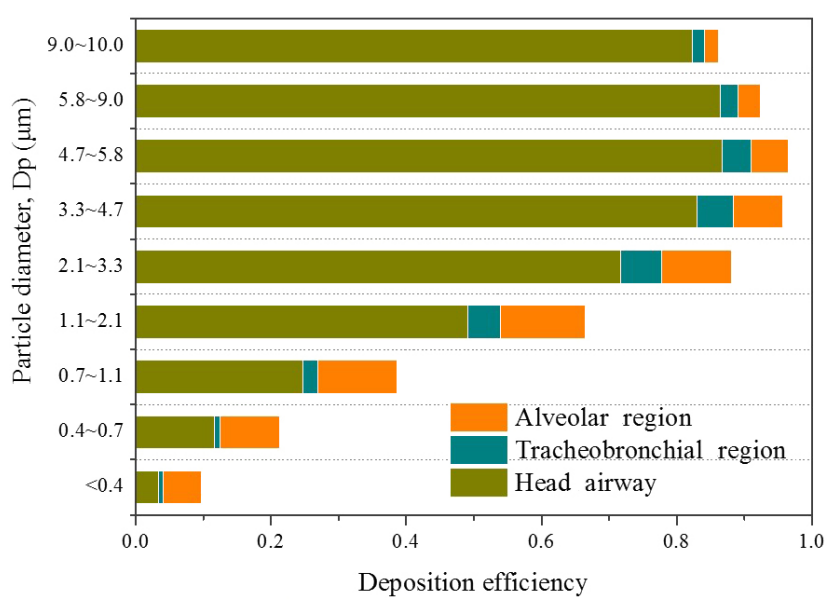

Figure 11. Deposition efficiencies (estimated by the ICRP model) of the size-segregated PAHs in the head airway, tracheobronchial region, and alveolar region.

ciency of PAHs across particle sizes. Generally, the deposition efficiency of PAHs increases with the particles size increase except for the alveolar region, in which the PAH deposition efficiency increases with particle size decrease. This suggests that smaller particles can easily pass the respiratory tract and be deposited in the alveolar region. This, combined with the fact that most five- and six-ring PAHs tend to adsorb on smaller particles, makes them more important for potential health damage.

We can utilize the LCR to estimate the exposure of PAHs through the inhalation of ambient particles. Figure 12 shows the LCR variations of inactive (breath rate: $0.45 \mathrm{~m}^{3} \mathrm{~h}^{-1}$ ) and active people (breath rate: $0.83 \mathrm{~m}^{3} \mathrm{~h}^{-1}$ ) during haze and non-haze periods. The curve of LCR displays a unimodal distribution with only one distinct peak located at 1.1$2.1 \mu \mathrm{m}$. Accumulation mode PAHs contribute about $54 \%$ of LCR, suggesting that accumulation particles are major carcinogenic-PAH carriers. After calculation, we can obtain an LCR value of $6.3( \pm 0.8) \times 10^{-7}$ in a normal respiratory condition $\left(0.45 \mathrm{~m}^{3} \mathrm{~h}^{-1}\right)$ during the Shanghai haze period, which approaches the cancer risk guideline value $\left(10^{-6}\right)$ (US EPA, 2005). As we know, the value of LCR depends strongly on the respiratory rate. If we apply an average respiratory rate of $0.83 \mathrm{~m}^{3} \mathrm{~h}^{-1}$ (for people who exercise outside) (Liu et al., 2007), the LCR value will arrive at $1.2( \pm 0.2) \times 10^{-6}$, which exceeds the cancer risk guideline value; especially on severe haze days the value can reach up to $1.5 \times 10^{-6}$. Note that this value is only for the size-resolved particulate PAHs, which are responsible for some of the respiratory risks posed by atmospheric PAHs. If the gaseous PAHs are also taken into account, the cancer risk will probably be much higher. In combination with previous PMF source analysis, we find that the sources of these PAHs are mainly biomass burning $(24 \%)$, coal combustion $(25 \%)$, and vehicular emission $(27 \%)$. This is consistent with the previous epidemiologi-
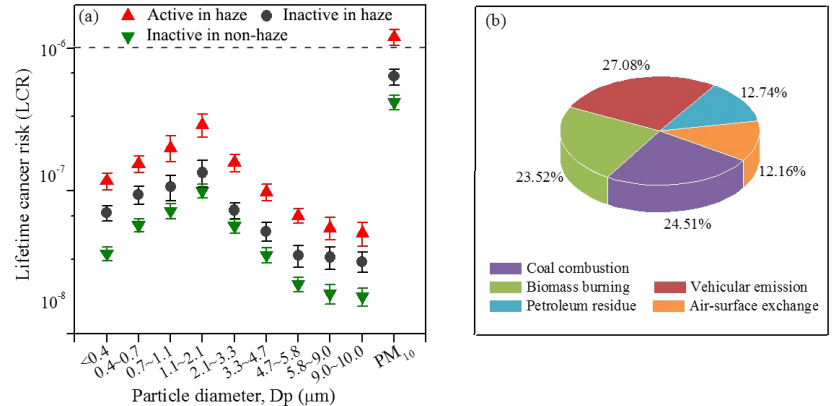

Figure 12. Panel (a): lifetime cancer risk (LCR) due to exposure to the size-segregated PAHs through inhalation for inactive and active people during haze and non-haze period. Panel (b): source contribution to accumulation mode PAHs during haze period by PMF analysis.

cal studies that smaller particles can lead to a greater risk of cardiovascular toxicity through breathing (Pope et al., 2009). Thus, it appears to be important to carry out stricter control of smaller-particle emissions, particularly aiming at the reduction of their releasing sources.

\section{Summary and conclusions}

We systematically investigated the particle size distribution of PAHs at a Shanghai urban site and identified their emission source. We found that size-resolved PAHs have a bimodal distribution, with one mode peak in the fine size range $(0.4-2.1 \mu \mathrm{m})$ and another one in the coarse size range (3.3-9 $\mu \mathrm{m})$. Multiple adsorption and absorption mechanisms controlled the PAH distribution among different sizes particles. The estimated LCR value for people who exercise outside was $1.2( \pm 0.2) \times 10^{-6}$, which exceeded the cancer risk guideline value $\left(10^{-6}\right)$. Accumulation mode PAHs contributed about $54 \%$ of LCR. Based on PMF results, their sources mainly came from biomass burning (24\%), coal combustion $(25 \%)$, and vehicular emission $(27 \%)$. This study could provide preliminary data for developing effective strategies for source control.

Acknowledgements. This work was supported by the National Natural Science Foundation of China (Nos. 21377028, 21577021, 21177025, 41475109), the Excellent Academic Leader Program (No. 14XD1400600), FP720 project (AMIS, IRSES-GA-2011), and the Major Research Project (No. 12DJ1400100) of the Science and Technology Commission of Shanghai Municipality.

Edited by: Y. Cheng 


\section{References}

Akyuz, M. and Cabuk, H.: Meteorological variations of $\mathrm{PM}_{2.5} / \mathrm{PM}_{10}$ concentrations and particle-associated polycyclic aromatic hydrocarbons in the atmospheric environment of Zonguldak, Turkey, J. Hazard. Mater., 170, 13-21, 2009.

Allen, J. O., Dookeran, K. M., Smith, K. A., Sarofim, A. F., Taghizadeh, K., and Lafleur, A. L.: Measurement of polycyclic aromatic hydrocarbons associated with size-segregated atmospheric aerosols in Massachusetts, Environ. Sci. Technol., 30, 1023-1031, 1996.

Arhami, M., Minguillón, M. C., Polidori, A., Schauer, J. J., Delfino, R. J., and Sioutas, C.: Organic compound characterization and source apportionment of indoor and outdoor quasi-ultrafine particulate matter in retirement homes of the Los Angeles Basin, Indoor Air, 20, 17-30, 2010.

Bi, X., Sheng, G., Peng, P. A., Chen, Y., and Fu, J.: Size distribution of n-alkanes and polycyclic aromatic hydrocarbons (PAHs) in urban and rural atmospheres of Guangzhou, China, Atmos. Environ., 39, 477-487, 2005.

Bostrom, C. E., Gerde, P., Hanberg, A., Jernstrom, B., Johansson, C., Kyrklund, T., Rannug, A., Tornqvist, M., Victorin, K., and Westerholm, R.: Cancer risk assessment, indicators, and guidelines for polycyclic aromatic hydrocarbons in the ambient air, Environ. Health Perspect., 110, 451-488, 2002.

Chan, A. W. H., Kautzman, K. E., Chhabra, P. S., Surratt, J. D., Chan, M. N., Crounse, J. D., Kürten, A., Wennberg, P. O., Flagan, R. C., and Seinfeld, J. H.: Secondary organic aerosol formation from photooxidation of naphthalene and alkylnaphthalenes: implications for oxidation of intermediate volatility organic compounds (IVOCs), Atmos. Chem. Phys., 9, 3049-3060, doi:10.5194/acp-9-3049-2009, 2009.

Chen, S. C. and Liao, C. M.: Health risk assessment on human exposed to environmental polycyclic aromatic hydrocarbons pollution sources, Sci. Total Environ., 366, 112-123, 2006.

Delgado-Saborit, J. M., Stark, C., and Harrison, R. M.: Use of a Versatile High Efficiency Multiparallel Denuder for the Sampling of PAHs in Ambient Air: Gas and Particle Phase Concentrations, Particle Size Distribution and Artifact Formation, Environ. Sci. Technol., 48, 499-507, 2013.

Ding, X., Wang, X. M., Xie, Z. Q., Xiang, C. H., Mai, B. X., Sun, L. G., Zheng, M., Sheng, G. Y., Fu, J. M., and Pöschl, U.: Atmospheric polycyclic aromatic hydrocarbons observed over the North Pacific Ocean and the Arctic area: Spatial distribution and source identification, Atmos. Environ., 41, 2061-2072, 2007.

Duan, J. C., Bi, X. H., Tan, J. H., Sheng, G. Y., and Fu, J. M.: The differences of the size distribution of polycyclic aromatic hydrocarbons (PAHs) between urban and rural sites of Guangzhou, China, Atmos. Res., 78, 190-203, 2005.

Duan, J. C., Bi, X. H., Tan, J. H., Sheng, G. Y., and Fu, J. M.: Seasonal variation on size distribution and concentration of PAHs in Guangzhou city, China, Chemosphere, 67, 614-622, 2007.

Fernández, P., Grimalt, J. O., and Vilanova, R. M.: Atmospheric Gas-Particle Partitioning of Polycyclic Aromatic Hydrocarbons in High Mountain Regions of Europe, Environ. Sci. Technol., 36, 1162-1168, 2002.

Garrido, A., Jimenez-Guerrero, P., and Ratola, N.: Levels, trends and health concerns of atmospheric PAHs in Europe, Atmos. Environ., 99, 474-484, 2014.
Geiser, M., Rothen-Rutishauser, B., Kapp, N., Schurch, S., Kreyling, W., Schulz, H., Semmler, M., Hof, V. I., Heyder, J., and Gehr, P.: Ultrafine particles cross cellular membranes by nonphagocytic mechanisms in lungs and in cultured cells, Environ. Health Perspect., 113, 1555-1560, 2005.

Gigliotti, C. L., Brunciak, P. A., Dachs, J., Glenn, T. R., Nelson, E. D., Totten, L. A., and Eisenreich, S. J.: Air-water exchange of polycyclic aromatic hydrocarbons in the New York-New Jersey, Usa, Harbor Estuary, Environ. Toxicol. Chem., 21, 235-244, 2002.

Gnauk, T., Muller, K., Bruggemann, E., Birmili, W., Weinhold, K., van Pinxteren, D., Loschau, G., Spindler, G., and Herrmann, H.: A study to discriminate local, urban and regional source contributions to the particulate matter concentrations in the city of Dresden, Germany, J. Atmos. Chem., 68, 199-231, 2011.

Gupta, S., Kumar, K., Srivastava, A., Srivastava, A., and Jain, V. K.: Size distribution and source apportionment of polycyclic aromatic hydrocarbons (PAHs) in aerosol particle samples from the atmospheric environment of Delhi, India, Sci. Total Environ., 409, 4674-4680, 2011.

Harrison, R. M., Smith, D. J. T., and Luhana, L.: Source apportionment of atmospheric polycyclic aromatic hydrocarbons collected from an urban location in Birmingham, UK, Environ. Sci. Technol., 30, 825-832, 1996.

Hien, T. T., Thanh, L. T., Kameda, T., Takenaka, N., and Bandow, H.: Distribution characteristics of polycyclic aromatic hydrocarbons with particle size in urban aerosols at the roadside in Ho Chi Minh City, Vietnam, Atmos. Environ., 41, 1575-1586, 2007.

Hytönen, K., Yli-Pirilä, P., Tissari, J., Gröhn, A., Riipinen, I., Lehtinen, K. E. J., and Jokiniemi, J.: Gas-Particle Distribution of PAHs in Wood Combustion Emission Determined with Annular Denuders, Filter, and Polyurethane Foam Adsorbent, Aerosol Sci. Technol., 43, 442-454, 2009.

International Commission on Radiological Protection (ICRP): $\mathrm{Hu}-$ man respiratory tract model for radiological protection, Publication 66, Elsevier Science, Oxford, UK, 1994.

Kameda, Y., Shirai, J., Komai, T., Nakanishi, J., and Masunaga, S.: Atmospheric polycyclic aromatic hydrocarbons: size distribution, estimation of their risk and their depositions to the human respiratory tract, Sci. Total Environ., 340, 71-80, 2005.

Kamens, R., Jang, M., Chien, C. J., and Leach, K.: Aerosol formation from the reaction of alpha-pinene and ozone using a gasphase kinetics aerosol partitioning model, Environ. Sci. Technol., 33, 1430-1438, 1999.

Kamens, R. M. and Jaoui, M.: Modeling aerosol formation from alpha-pinene plus NOx in the presence of natural sunlight using gas-phase kinetics and gas-particle partitioning theory, Environ. Sci. Technol., 35, 1394-1405, 2001.

Kavouras, I. G., Mihalopoulos, N., and Stephanou, E. G.: Secondary organic aerosol formation vs primary organic aerosol emission: In situ evidence for the chemical coupling between monoterpene acidic photooxidation products and new particle formation over forests, Environ. Sci. Technol., 33, 1028-1037, 1999.

Kawanaka, Y., Matsumoto, E., Sakamoto, K., Wang, N., and Yun, S. J.: Size distributions of mutagenic compounds and mutagenicity in atmospheric particulate matter collected with a low-pressure cascade impactor, Atmos. Environ., 38, 2125-2132, 2004.

Kawanaka, Y., Tsuchiya, Y., Yun, S.-J., and Sakamoto, K.: Size Distributions of Polycyclic Aromatic Hydrocarbons in the At- 
mosphere and Estimation of the Contribution of Ultrafine Particles to Their Lung Deposition, Environ. Sci. Technol., 43, 68516856, 2009.

Keshtkar, H. and Ashbaugh, L. L.: Size distribution of polycyclic aromatic hydrocarbon particulate emission factors from agricultural burning, Atmos. Environ., 41, 2729-2739, 2007.

Kong, S., Lu, B., Ji, Y., Bai, Z., Xu, Y., Liu, Y., and Jiang, H.: Distribution and sources of polycyclic aromatic hydrocarbons in sizedifferentiated re-suspended dust on building surfaces in an oilfield city, China, Atmos. Environ., 55, 7-16, 2012.

Kong, S. F., Shi, J. W., Lu, B., Qiu, W. G., Zhang, B. S., Peng, Y., Zhang, B. W., and Bai, Z. P.: Characterization of PAHs within $\mathrm{PM}_{10}$ fraction for ashes from coke production, iron smelt, heating station and power plant stacks in Liaoning Province, China, Atmos. Environ., 45, 3777-3785, 2011.

Ladji, R., Yassaa, N., Balducci, C., and Cecinato, A.: Particle size distribution of n-alkanes and polycyclic aromatic hydrocarbons (PAHS) in urban and industrial aerosol of Algiers, Algeria, Environ. Sci. Pollut. Res., 21, 1819-1832, 2014.

Larsen, R. K. and Baker, J. E.: Source apportionment of polycyclic aromatic hydrocarbons in the urban atmosphere: A comparison of three methods, Environ. Sci. Technol., 37, 1873-1881, 2003.

Lee, J. Y., Shin, H. J., Bae, S. Y., Kim, Y. P., and Kang, C. H.: Seasonal variation of particle size distributions of PAHs at Seoul, Korea, Air Qual. Atmos. Hlth., 1, 57-68, 2008.

Li, J., Zhang, G., Li, X. D., Qi, S. H., Liu, G. Q., and Peng, X. Z.: Source seasonality of polycyclic aromatic hydrocarbons (PAHs) in a subtropical city, Guangzhou, South China, Sci. Total Environ., 355, 145-155, 2006.

Li, P. F., Li, X., Yang, C. Y., Wang, X. J., Chen, J. M., and Collett, J. L.: Fog water chemistry in Shanghai, Atmos. Environ., 45, 40344041, 2011.

Li, X., Li, P., Yan, L., Chen, J., Cheng, T., and Xu, S.: Characterization of polycyclic aromatic hydrocarbons in fog-rain events, $\mathrm{J}$. Environ. Monit., 13, 2988-2993, 2011.

Lin, T., Hu, L. M., Guo, Z. G., Qin, Y. W., Yang, Z. S., Zhang, G., and Zheng, M.: Sources of polycyclic aromatic hydrocarbons to sediments of the Bohai and Yellow Seas in East Asia, J. Geophys. Res., 116, D23305, doi:10.1029/2011jd015722, 2011.

Lindgren, F., Geladi, P., Berglund, A., Sjostrom, M., and Wold, S.: Interactive Variable Selection (Ivs) for Pls .2. Chemical Applications, J. Chemometr., 9, 331-342, 1995.

Liu, Y. N., Tao, S., Dou, H., Zhang, T. W., Zhang, X. L., and Dawson, R.: Exposure of traffic police to Polycyclic aromatic hydrocarbons in Beijing, China, Chemosphere, 66, 1922-1928, 2007.

Ma, W. L., Li, Y. F., Qi, H., Sun, D. Z., Liu, L. Y., and Wang, D. G.: Seasonal variations of sources of polycyclic aromatic hydrocarbons (PAHs) to a northeastern urban city, China, Chemosphere, 79, 441-447, 2010.

Mai, B. X., Qi, S. H., Zeng, E. Y., Yang, Q. S., Zhang, G., Fu, J. M., Sheng, G. Y., Peng, P. N., and Wang, Z. S.: Distribution of polycyclic aromatic hydrocarbons in the coastal region off Macao, China: Assessment of input sources and transport pathways using compositional analysis, Environ. Sci. Technol., 37, 4855-4863, 2003.

McWhinney, R. D., Zhou, S., and Abbatt, J. P. D.: Naphthalene SOA: redox activity and naphthoquinone gas-particle partitioning, Atmos. Chem. Phys., 13, 9731-9744, doi:10.5194/acp-139731-2013, 2013.
Mesquita, S. R., van Drooge, B. L., Reche, C., Guimarães, L., Grimalt, J. O., Barata, C., and Piña, B.: Toxic assessment of urban atmospheric particle-bound PAHs: Relevance of composition and particle size in Barcelona (Spain), Environ. Pollut., 184, 555562, 2014.

Miguel, A. H., Eiguren-Fernandez, A., Jaques, P. A., Froines, J. R., Grant, B. L., Mayo, P. R., and Sioutas, C.: Seasonal variation of the particle size distribution of polycyclic aromatic hydrocarbons and of major aerosol species in Claremont, California, Atmos. Environ., 38, 3241-3251, 2004.

Nemmar, A., Hoet, P. H. M., Vanquickenborne, B., Dinsdale, D., Thomeer, M., Hoylaerts, M. F., Vanbilloen, H., Mortelmans, L., and Nemery, B.: Passage of inhaled particles into the blood circulation in humans, Circulation, 105, 411-414, 2002.

Nisbet, I. C. T. and Lagoy, P. K.: Toxic equivalency factors (TEFs) for polycyclic aromatic hydrocarbons (PAHs), Regul. Toxicol. Pharm., 16, 290-300, 1992.

Offenberg, J. H. and Baker, J. E.: Aerosol Size Distributions of Polycyclic Aromatic Hydrocarbons in Urban and Over-Water Atmospheres, Environ. Sci. Technol., 33, 3324-3331, 1999.

Oliveira, C., Martins, N., Tavares, J., Pio, C., Cerqueira, M., Matos, M., Silva, H., Oliveira, C., and Camoes, F.: Size distribution of polycyclic aromatic hydrocarbons in a roadway tunnel in Lisbon, Portugal, Chemosphere, 83, 1588-1596, 2011.

Paatero, P. and Tapper, U.: Positive Matrix Factorization a Nonnegative Factor Model with Optimal Utilization Of Error-Estimates Of Data Values, Environmetrics, 5, 111-126, doi:10.1002/env.3170050203, 1994.

Pope, C. A., Ezzati, M., and Dockery, D. W.: Fine-Particulate Air Pollution and Life Expectancy in the United States, New Engl. J. Med., 360, 376-386, 2009.

Poulain, L., Iinuma, Y., Müller, K., Birmili, W., Weinhold, K., Brüggemann, E., Gnauk, T., Hausmann, A., Löschau, G., Wiedensohler, A., and Herrmann, H.: Diurnal variations of ambient particulate wood burning emissions and their contribution to the concentration of Polycyclic Aromatic Hydrocarbons (PAHs) in Seiffen, Germany, Atmos. Chem. Phys., 11, 12697-12713, doi:10.5194/acp-11-12697-2011, 2011.

Ravindra, K., Sokhi, R., and Van Grieken, R.: Atmospheric polycyclic aromatic hydrocarbons: Source attribution, emission factors and regulation, Atmos. Environ., 42, 2895-2921, 2008.

Sanderson, E. G. and Farant, J. P.: Atmospheric Size Distribution of PAHs:? Evidence of a High-Volume Sampling Artifact, Environ. Sci. Technol., 39, 7631-7637, 2005.

Sheesley, R. J., Kruså, M., Krecl, P., Johansson, C., and Gustafsson, Ö.: Source apportionment of elevated wintertime PAHs by compound-specific radiocarbon analysis, Atmos. Chem. Phys., 9, 3347-3356, doi:10.5194/acp-9-3347-2009, 2009.

Shen, G., Wang, W., Yang, Y., Ding, J., Xue, M., Min, Y., Zhu, C., Shen, H., Li, W., Wang, B., Wang, R., Wang, X., Tao, S., and Russell, A. G.: Emissions of PAHs from Indoor Crop Residue Burning in a Typical Rural Stove: Emission Factors, Size Distributions, and Gas-Particle Partitioning, Environ. Sci. Technol., 45, 1206-1212, 2011.

Sofowote, U. M., McCarry, B. E., and Marvin, C. H.: Source apportionment of PAH in Hamilton Harbour suspended sediments: Comparison of two factor analysis methods, Environ. Sci. Technol., 42, 6007-6014, 2008. 
Theodosi, C., Grivas, G., Zarmpas, P., Chaloulakou, A., and Mihalopoulos, N.: Mass and chemical composition of sizesegregated aerosols $\left(\mathrm{PM}_{1}, \mathrm{PM}_{2.5}, \mathrm{PM}_{10}\right)$ over Athens, Greece: local versus regional sources, Atmos. Chem. Phys., 11, 1189511911, doi:10.5194/acp-11-11895-2011, 2011.

Teixeira, E. C., Agudelo-Castañeda, D. M., Fachel, J. M. G., Leal, K. L., Garcia, K. O., and Wiegand, F.: Source identification and seasonal variation of polycyclic aromatic hydrocarbons associated with atmospheric fine and coarse particles in the metropolitan area of Porto Alegre, RS, Brazil, Atmos. Res., 118, 390-403, 2012.

US EPA (U.S. Environmental Protection Agency): Risk assessment guidance for super fund volume I human health evaluation manual, part A, EPA/540/1-89/002, Office of Emergency and Remedial Response, Washington, D.C, USA, 1989.

US EPA (U.S. Environmental Protection Agency): Guidelines for carcinogen risk assessment. EPA/630/P-03/001F, Risk Assessment Forum, Washington, D.C, USA, 2005.

van Drooge, B. L. and Ballesta, P. P.: Seasonal and Daily Source Apportionment of Polycyclic Aromatic Hydrocarbon Concentrations in $\mathrm{PM}_{10}$ in a Semirural European Area, Environ. Sci. Technol., 43, 7310-7316, 2009.

Venkataraman, C. and Friedlander, S. K.: Size Distributions of Polycyclic Aromatic-Hydrocarbons and Elemental Carbon. 2. Ambient Measurements and Effects of Atmospheric Processes, Environ. Sci. Technol., 28, 563-572, 1994.

Venkataraman, C., Lyons, J. M., and Friedlander, S. K.: Size Distributions of Polycyclic Aromatic-Hydrocarbons and Elemental Carbon. 1. Sampling, Measurement Methods, and Source Characterization, Environ. Sci. Technol., 28, 555-562, 1994.

Venkataraman, C., Thomas, S., and Kulkarni, P.: Size distributions of polycyclic aromatic hydrocarbons - Gas/particle partitioning to urban aerosols, J. Aerosol Sci., 30, 759-770, 1999.

Venkataraman, C., Negi, G., Sardar, S. B., and Rastogi, R.: Size distributions of polycyclic aromatic hydrocarbons in aerosol emissions from biofuel combustion, J. Aerosol Sci, 33, 503-518, 2002.

Wang, G., Kawamura, K., Xie, M., Hu, S., Gao, S., Cao, J., An, Z., and Wang, Z.: Size-distributions of $n$-alkanes, PAHs and hopanes and their sources in the urban, mountain and marine atmospheres over East Asia, Atmos. Chem. Phys., 9, 8869-8882, doi:10.5194/acp-9-8869-2009, 2009.

Wang, X., Chen, J., Cheng, T., Zhang, R., and Wang, X.: Particle number concentration, size distribution and chemical composition during haze and photochemical smog episodes in Shanghai, J. Environ. Sci.-China, 26, 1894-1902, 2014.
WHO: Air Quality Guidelines - Global Update 2005. Particulate matter, ozone, nitrogen dioxide and sulfur dioxide. Copenhagen, World Health Organization (WHO) Regional Office for Europe, ISBN 92890 21926, available at: http://www.who.int/ phe/health_topics/outdoorair/outdoorair_aqg/en/ (last access: 7 March 2016), 2006.

Wilson, J. G., Kingham, S., Pearce, J., and Sturman, A. P.: A review of intraurban variations in particulate air pollution: Implications for epidemiological research, Atmos. Environ., 39, 6444-6462, 2005.

Wu, D., Wang, Z., Chen, J., Kong, S., Fu, X., Deng, H., Shao, G., and $\mathrm{Wu}, \mathrm{G} .:$ Polycyclic aromatic hydrocarbons (PAHs) in atmospheric $\mathrm{PM}_{2.5}$ and $\mathrm{PM}_{10}$ at a coal-based industrial city: Implication for PAH control at industrial agglomeration regions, China, Atmos. Res., 149, 217-229, 2014.

Wu, S. P., Tao, S., and Liu, W. X.: Particle size distributions of polycyclic aromatic hydrocarbons in rural and urban atmosphere of Tianjin, China, Chemosphere, 62, 357-367, 2006.

Yang, H. H., Lai, S. O., Hsieh, L. T., Hsueh, H. J., and Chi, T. W. Profiles of PAH emission from steel and iron industries, Chemosphere, 48, 1061-1074, 2002.

Yu, H. and Yu, J. Z.: Polycyclic aromatic hydrocarbons in urban atmosphere of Guangzhou, China: Size distribution characteristics and size-resolved gas-particle partitioning, Atmos. Environ., 54, 194-200, 2012.

Yu, J. Z., Cocker, D. R., Griffin, R. J., Flagan, R. C., and Seinfeld, J. H.: Gas-phase ozone oxidation of monoterpenes: Gaseous and particulate products, J. Atmos. Chem., 34, 207-258, 1999.

Zakaria, M. P., Takada, H., Tsutsumi, S., Ohno, K., Yamada, J., Kouno, E., and Kumata, H.: Distribution of polycyclic aromatic hydrocarbons (PAHs) in rivers and estuaries in Malaysia: A widespread input of petrogenic PAHs, Environ. Sci. Technol., 36, 1907-1918, 2002.

Zhang, K., Zhang, B. Z., Li, S. M., Wong, C. S., and Zeng, E. Y.: Calculated respiratory exposure to indoor size-fractioned polycyclic aromatic hydrocarbons in an urban environment, Sci. Total Environ., 431, 245-251, 2012.

Zhang, R., Khalizov, A., Wang, L., Hu, M., and Xu, W.: Nucleation and growth of nanoparticles in the atmosphere, Chem. Rev., 112 1957-2011, doi:10.1021/cr2001756, 2012.

Zhou, J. B., Wang, T. G., Zhang, Y. P., Mao, T., Huang, Y. B., Zhong, N. N., and Simoneit, B. R. T.: Sources and seasonal changes in the distributions of aliphatic and polycyclic aromatic hydrocarbons in size fractions of atmospheric particles of Beijing, China, Environ. Eng. Sci., 25, 207-220, 2008. 